\title{
Case Report \\ Endovascular Management of Middle Aortic Syndrome Presenting with Uncontrolled Hypertension
}

\author{
Owen S. Glotzer $\mathbb{D}^{D}$, Kathryn Bowser, F. Todd Harad, and Sandra Weiss
}

The Heart and Vascular Center, Christiana Care, Newark, DE 19713, USA

Correspondence should be addressed to Owen S. Glotzer; owen.s.glotzer@christianacare.org

Received 13 July 2018; Accepted 30 September 2018; Published 28 October 2018

Academic Editor: Nikolaos Papanas

Copyright (C) 2018 Owen S. Glotzer et al. This is an open access article distributed under the Creative Commons Attribution License, which permits unrestricted use, distribution, and reproduction in any medium, provided the original work is properly cited.

\begin{abstract}
Middle Aortic Syndrome is a rare vascular disorder consisting of narrowing or stenosis of the distal thoracic or abdominal aorta. It is described in the literature in the form of case studies and case series. The authors present an unusual case of Middle Aortic Syndrome attributed to Takayasu's arteritis in a 60-year-old female who presented to the emergency department with uncontrolled hypertension. Traditional intervention involves open surgical bypass. This case study reviews the published literature on this rare syndrome and illustrates a successful alternative to open surgery through an endovascular approach.
\end{abstract}

\section{Introduction}

Middle Aortic Syndrome is a rare vascular disorder consisting of narrowing or stenosis of the distal thoracic or abdominal aorta. This constellation of anatomic abnormalities and symptoms is generally attributed to either a developmental/congenital disorder or to inflammatory vasculitis such as Takayasu's arteritis (TAK). Organ and muscle malperfusion distal to the affected aorta can lead most commonly to lower extremity claudication, resistant hypertension, and abdominal pain $[1,2]$. It is classically identified during the first three decades of life and has been traditionally treated with open surgery [3-6]. The authors present a unique case of severe abdominal aortic stenosis in a 60-year-old female who presented with uncontrolled hypertension.

\section{Case Report}

A 60-year-old female presented to the outpatient cardiology clinic for evaluation of worsening chronic hypertension for which she had been on hydrochlorothiazide/Valsartan for 10 years. Her systolic blood pressure exceeded $200 \mathrm{mmHg}$ in the office, and aggressive medical therapy was initiated in the outpatient setting. She returned to the emergency department the following day with headache and malaise and systolic blood pressure above $200 \mathrm{mmHg}$ for which she was treated and discharged.
She returned to the emergency department again 5 days later, this time with complaints of word finding difficulty, blurred vision, and lower extremity tingling. Her blood pressure on presentation was $216 / 81 \mathrm{mmHg}$. She was admitted, and workup demonstrated no acute intracranial process or carotid stenosis. Echocardiography revealed mild concentric left ventricular hypertrophy with a preserved ejection fraction. Her blood pressure continued to be refractory to medical therapy despite five antihypertensive agents and eventual initiation of an esmolol infusion. A renal artery ultrasound identified renal artery stenosis with flow at the arterial origin measuring $350 \mathrm{~cm} / \mathrm{s}$ on the right and $208 \mathrm{~cm} / \mathrm{s}$ on the left (Table 1); flow velocity in the supraceliac aorta was also noted to be elevated. She had no history of kidney disease and no elevation of her creatinine. Vascular surgery was consulted and a history of lower extremity claudication was elicited. On exam she had weak but palpable femoral pulses and an audible abdominal aortic bruit; ankle-brachial index measurements were deferred and the patient was scheduled for angiogram.

The patient underwent aortography the following day and on selective angiography the renal arteries were found to be widely patent. Significant stenosis was identified at the distal thoracic aorta extending into the abdominal aorta but terminating proximal to the celiac trunk. The degree of stenosis was deemed to be greater than $90 \%$ and a pressure gradient between the upper extremity and intra-aortic measurements 


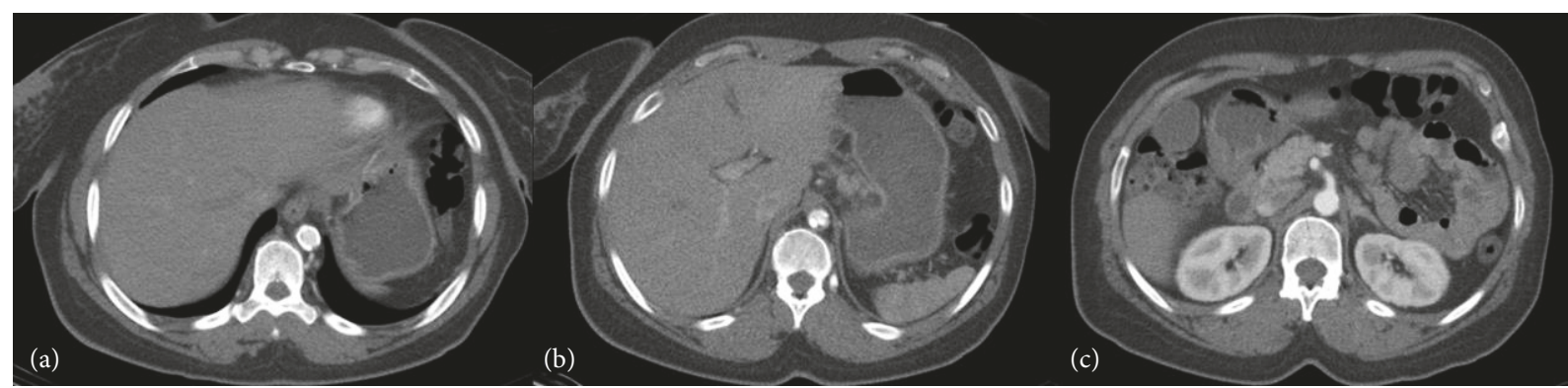

Figure 1: (a) Aorta proximal to stenosis with circumferential calcification measuring $9 \mathrm{~mm}$ lumen and 14 mm external diameter. (b) Aorta at the level stenosis with a luminal diameter of $5 \mathrm{~mm}$. (c) Aorta distal to stenosis with a $14 \mathrm{~mm}$ wall and a patent lumen.

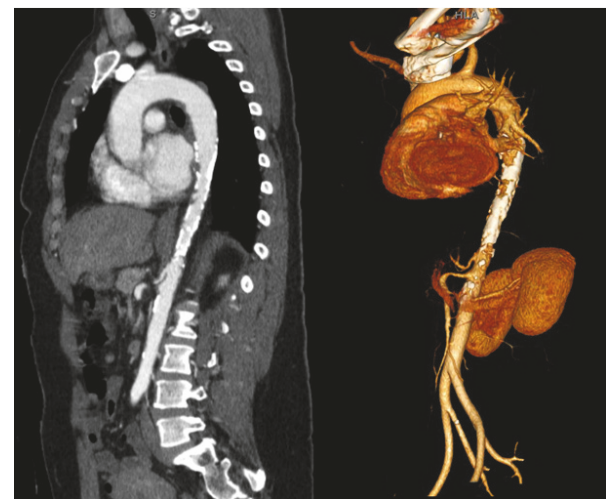

Figure 2: CTA of showing the area of stenosis in the supraceliac aorta with $3 \mathrm{D}$ reconstruction.

TABLE 1: Renal artery duplex measurements.

\begin{tabular}{lcc}
\hline Criteria & Right Kidney & Left Kidney \\
\hline Size $(\mathrm{cm})$ & 8.71 & 10.26 \\
Velocity $(\mathrm{cm} / \mathrm{s})$ & & \\
$\quad$ Origin & 350 & 208 \\
$\quad$ Proximal & 175 & 211 \\
Mid & 49 & 112 \\
$\quad$ Distal & 41 & $\mathrm{NR}$ \\
RI & & \\
$\quad$ Upper & 0.64 & 0.59 \\
Mid & 0.69 & 0.57 \\
$\quad$ Lower & 0.71 & 0.50 \\
RAR & 2.69 & 1.67 \\
\hline
\end{tabular}

$R I=$ resistive indices, $R A R=$ renal to aortic ratio, and $N R=$ not recorded

exceeded $100 \mathrm{mmHg}$. CTA was subsequently performed to evaluate the extent of the lesion and confirmed a stenosis $1.3 \mathrm{~cm}$ proximal to the celiac origin measuring $5 \mathrm{~mm}$ at its narrowest point (Figures 1 and 2). The patient underwent arteriogram; the stenosis was successfully navigated and a Protege $14 \times 40 \times 12 \mathrm{~mm}$ nitinol stent (Medtronic Vascular, Santa Rosa CA) was delivered followed by a $10 \mathrm{~mm}$ postdilation balloon. A completion arteriogram demonstrated excellent flow across the stent.
After stenting, the patients' systolic blood pressure was $140-160 \mathrm{mmHg}$, and she experienced resolution of her lower extremity claudication. She was discharged from the hospital on Aspirin and Plavix and a blood pressure regimen consisting of lisinopril, hydralazine, amlodipine, and carvedilol.

She was lost to follow-up until two years later when she returned to the hospital with a blood pressure of $220 / 85 \mathrm{mmHg}$, with complaints of chest discomfort. CTA demonstrated stenosis in the distal portion of the aortic stent. An angiogram was performed, and the stent was ballooned to $12 \mathrm{~mm}$. Pressure gradient measurements taken before and after dilatation decreased from $60 \mathrm{mmHg}$ to $20 \mathrm{mmHg}$. On follow-up one year later, she continued to experience excellent blood pressure control.

\section{Discussion}

Middle Aortic Syndrome is a rare clinical presentation with only case studies and case series reported in the literature [4, 5, 7-9]. There is no characteristic presentation, but this syndrome can lead to severe hypertension, diminished or absent femoral pulses, lower extremity claudication, incongruent extremity pressure measurements, and audible arterial bruits. Laboratory analysis can show elevation of inflammatory markers such as erythrocyte sedimentation rate (ESR) and Creactive protein (CRP). [10]

The classic imaging findings of Middle Aortic Syndrome have been described as an hour glass shaped aorta identified on CT scan or arteriography. Classification of this syndrome is based on the most proximal portion of the aorta affected $[5,6]$. Distal lesions are more often associated with renal and/or splanchnic arterial disease, which is consistent with the case presented here as the infraceliac aorta was of normal caliber and there was no associated narrowing in the renal or splanchnic vasculature.

It is difficult to attribute the location and degree of narrowing to atherosclerotic disease alone given her lack of risk factors such as obesity, diabetes mellitus, or smoking history and lack of arterial calcification in other areas. Attributing her stenosis to congenital anomaly seems even more implausible given her age at presentation. Although large vessel arteritis is generally diagnosed in patients before the age of 30, adult onset TAK is well described [3, 11-13]. According to the American College of Rheumatology, three of six criteria are required for the diagnosis of TAK: onset 
at or before 40 years of age, $10 \mathrm{mmHg}$ difference in brachial pressures, decreased pulsation in a brachial artery, subclavian or aortic bruit, narrowing/occlusions of the aorta, its primary branches or major proximal arteries in the extremities, and claudication of the extremities [14-16]. Although ESR and CRP were never obtained during her workup, according to these criteria the patient meets criteria for TAK.

Another point of interest is the ultrasound demonstrating flow acceleration in the renal arteries, with a lack of renal stenosis present on arteriography or CT. The authors attribute this finding to poststenotic flow acceleration centered at the level of the renal arteries, which is further supported by follow-up duplex study that demonstrates decreased flow velocity through the renal arteries after placement of the aortic stent. The native aorta distal to the stenosed segment measured $14 \mathrm{~mm}$; as such, increased velocity is expected through a $10 \mathrm{~mm}$ stent. Placement of a larger stent was thought to pose too high a risk for iatrogenic trauma.

Traditional intervention consists of open surgery with bypass grafting, interposition grafting, or patch aortoplasty $[5,11,17-20]$. However, given the extent and complexity of these procedures, mortality rates have been quoted as high as $13 \%$ [21]. More recently, endovascular intervention has been performed with positive results [2, 22-25]. The extent of the lesion, involvement of visceral and/or renal arteries, age, and comorbidities of the patient need to be taken into consideration when selecting the most appropriate therapy [26]. The patient described here achieved blood pressure control and experienced resolution of her associated symptoms; despite the need for reintervention the authors maintain that endovascular therapy was the appropriate approach in this instance. The longevity of aortic stenting for stenotic lesions has yet to be determined, and some patients will require reintervention, as was true in this case. The decreased risk of morbidity and mortality justifies the endovascular approach as the initial intervention in elderly patients or those with significant comorbidities.

\section{Conclusion}

Middle Aortic Syndrome is a rare entity with an often unclear clinical presentation. The authors of this manuscript add this presentation to the literature regarding hypertension stemming from significant stenosis of the abdominal aorta. This case study demonstrates that the endovascular approach should be viewed as an appropriate early step in the management of hypertension due to aortic stenosis for patients with anatomically amenable lesions, who are at an increased risk of complications from open surgery.

\section{Conflicts of Interest}

The authors declare that there are no conflicts of interest regarding the publication of this paper.

\section{References}

[1] T. T. Terramani, A. Salim, D. B. Hood, V. L. Rowe, and F. A. Weaver, "Hypoplasia of the descending thoracic and abdominal aorta: A report of two cases and review of the literature," Journal of Vascular Surgery, vol. 36, no. 4, pp. 844-848, 2002.

[2] W. Che, H. Xiong, X. Jiang et al., "Stenting for middle aortic syndrome caused by Takayasu arteritis-immediate and longterm outcomes," Catheterization and Cardiovascular Interventions, vol. 91, pp. 623-631, 2018.

[3] J. E. Connolly, S. E. Wilson, P. L. Lawrence, and R. M. Fujitani, "Middle aortic syndrome: Distal thoracic and abdominal coarctation, a disorder with multiple etiologies," Journal of the American College of Surgeons, vol. 194, no. 6, pp. 774-781, 2002.

[4] H. D. Kim, M. Kim, S. Kim et al., "Resistant hypertension caused by stenosis of the aorta in elderly women: three case reports," Clinical Hypertension, vol. 20, no. 1, 2014.

[5] J. C. Stanley, E. Criado, J. L. Eliason, G. R. Upchurch Jr., R. Berguer, and J. E. Rectenwald, "Abdominal aortic coarctation: Surgical treatment of 53 patients with a thoracoabdominal bypass, patch aortoplasty, or interposition aortoaortic graft," Journal of Vascular Surgery, vol. 48, no. 5, pp. 1073-1082, 2008.

[6] L. M. Graham, G. B. Zelenock, E. E. Erlandson, A. G. Coran, S. M. Lindenauer, and J. C. Stanley, "Abdominal aortic coarctation and segmental hypoplasia," Surgery, vol. 86, no. 4, pp. 519-529, 1979.

[7] K. Uwabe, O. Okada, and M. Harada, "Ascending to descending aorta bypass for middle aortic syndrome," Circulation Journal, vol. 71, no. 7, pp. 1162-1163, 2007.

[8] K. C. A. Cheng and Y. L. Li, "Mid-aortic syndrome secondary to Takayasu's disease," BMJ Case Reports, vol. 2017, 2017.

[9] K. Yakut and I. Erdogan, "Case report of a rarely seen long segment middle aortic syndrome," Turk Kardiyoloji Dernegi Arsivi-Archives of the Turkish Society of Cardiology, vol. 45, no. 2, pp. 181-183, 2017.

[10] R. Serra, L. Butrico, F. Fugetto et al., "Updates in pathophysiology, diagnosis and management of takayasu arteritis," Annals of Vascular Surgery, vol. 35, pp. 210-225, 2016.

[11] B. Segers, M. Derluyn, J.-P. Barroy, and A. P. Brunet, "Isolated supradiaphragmatic descending thoracic aorta stenosis in a Takayasu's disease: Surgical cure," European Journal of CardioThoracic Surgery, vol. 20, no. 6, pp. 1243-1245, 2001.

[12] Y. Qi, L. Yang, H. Zhang et al., "The presentation and management of hypertension in a large cohort of Takayasu arteritis," Clinical Rheumatology, vol. 37, no. 10, pp. 2781-2788, 2018.

[13] F. A. Aeschlimann, L. Barra, R. Alsolaimani et al., "Presentation and disease course of childhood- versus adult-onset Takayasu Arteritis," Arthritis \& Rheumatology, 2018.

[14] W. P. Arend, B. A. Michel, D. A. Bloch et al., "The American College of Rheumatology 1990 criteria for the classification of Takayasu arteritis," Arthritis \& Rheumatology, vol. 33, no. 8, pp. 1129-1134, 1990.

[15] K. L. Huang, Y. C. Lin, and K. L. Oller, "An Unusual Cause of Abdominal Pain in a Young, Hypertensive Female," Gastroenterology, vol. 154, no. 3, pp. e10-e11, 2018.

[16] B. Patel, A. Tiwari, S. R. K. Dubey, G. C. Bhatt, P. Tiwari, and B. D. Bhan, "Takayasu arteritis presenting with malignant hypertension; a rare manifestation of a rare disease: a case report and review of the literature," Tropical Doctor, vol. 47, no. 1, pp. 60-63, 2017.

[17] C. A. Hinojosa, J. E. Anaya-Ayala, A. Torres-Machorro, R. Lizola, and H. Laparra-Escareno, "Middle aortic syndrome in Takayasu's arteritis: Report of two surgical cases," Annals of Vascular Surgery, vol. 34, pp. 270.e13-270.e17, 2016. 
[18] A. Chitrakar, K. R. Shrestha, and U. K. Shrestha, "Middle aortic syndrome with renal artery stenosis," Journal of Surgical Case Reports, vol. 2017, no. 9, 2017.

[19] K. T. Delis and P. Gloviczki, "Middle Aortic Syndrome: From Presentation to Contemporary Open Surgical and Endovascular Treatment," Perspectives in Vascular Surgery and Endovascular Therapy, vol. 17, no. 3, pp. 187-203, 2005.

[20] H. J. Kim, J.-W. Choi, H. Y. Hwang, and H. Ahn, "Extraanatomic ascending aorta to abdominal aorta bypass in Takayasu arteritis patients with mid-aortic syndrome," The Korean Journal of Thoracic and Cardiovascular Surgery, vol. 50, no. 4, pp. 270-274, 2017.

[21] A. V. Pokrovsky, T. A. Sultanaliev, and A. A. Spiridonov, "Surgical treatment of vasorenal hypertension in nonspecific aorto-arteritis (Takayasu's disease)," Journal of Cardiovascular Surgery, vol. 24, no. 2, pp. 111-118, 1983.

[22] M. Di Santo, É. V. Stelmaszewski, and A. Villa, "Endovascular intervention in takayasu arteritis. Case report," Archivos Argentinos de Pediatría, vol. 114, no. 3, pp. e147-e150, 2016.

[23] Y. P. Diao, Y. X. Chen, S. Yan et al., "Efficacy and safety analysis of surgical bypass and endovascular management in the treatment of 116 Takayasu arteritis," Zhonghua Yi Xue Za Zhi, vol. 96, no. 6, pp. 447-450, 2016.

[24] J. Jung, G. Song, S. Choi, Y. Lee, and J. Kim, "Endovascular intervention versus surgery in patients with takayasu arteritis: a meta-analysis," European Journal of Vascular and Endovascular Surgery, vol. 55, no. 6, pp. 888-899, 2018.

[25] D. Saadoun, M. Lambert, T. Mirault et al., "Retrospective analysis of surgery versus endovascular intervention in Takayasu arteritis a multicenter experience," Circulation, vol. 125, no. 6, pp. 813-819, 2012.

[26] S. M. Kim, I. M. Jung, A. Han et al., "Surgical Treatment of Middle Aortic Syndrome with Takayasu Arteritis or Midaortic Dysplastic Syndrome," European Journal of Vascular and Endovascular Surgery, vol. 50, no. 2, pp. 206-212, 2015. 


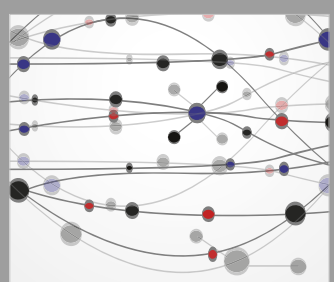

The Scientific World Journal
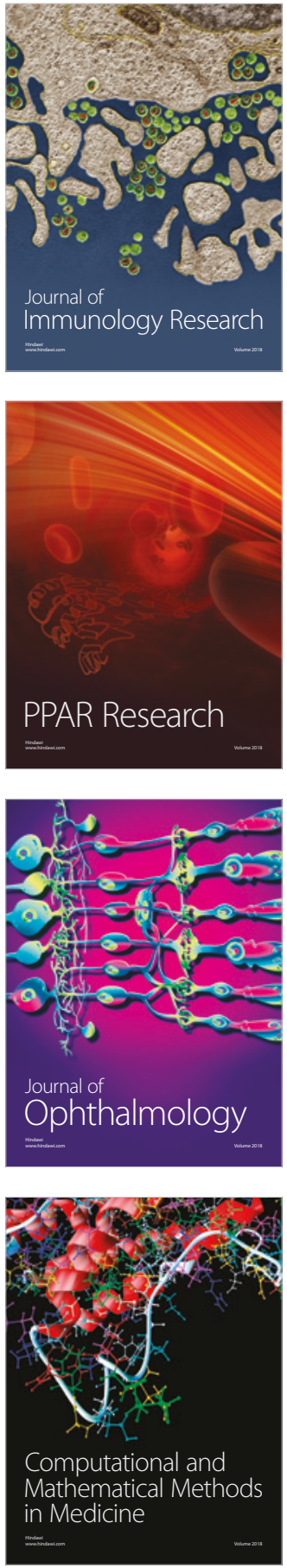

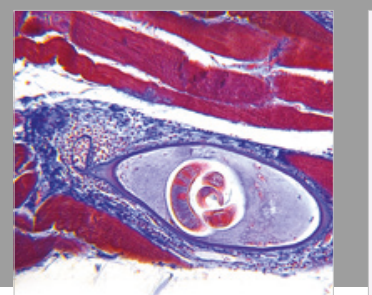

Gastroenterology Research and Practice

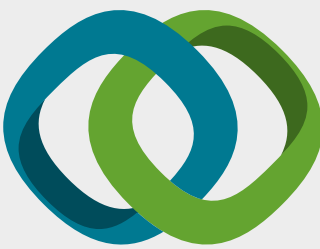

\section{Hindawi}

Submit your manuscripts at

www.hindawi.com
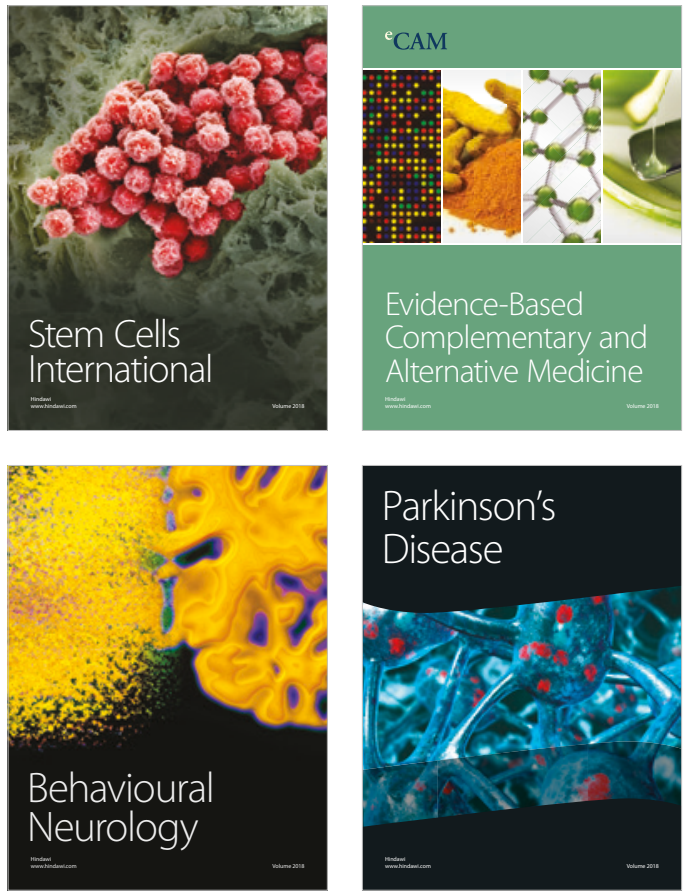

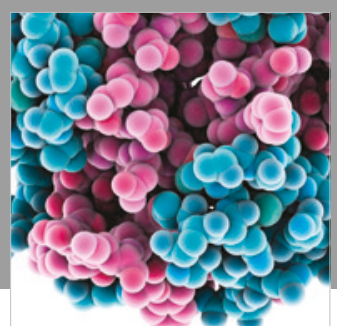

ournal of

Diabetes Research

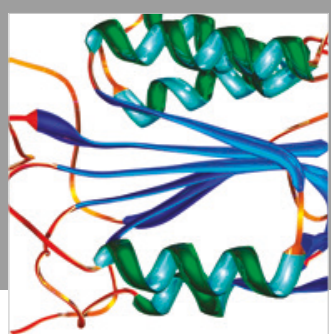

Disease Markers
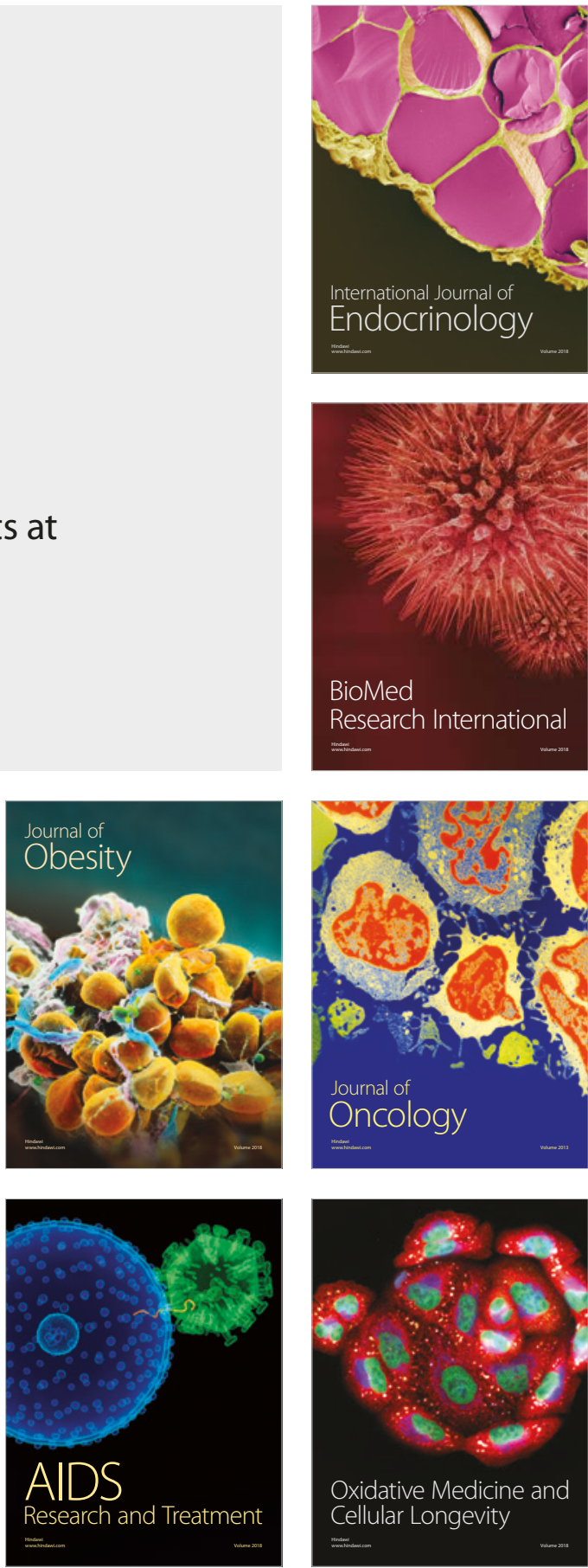